\title{
Mixing and administration times of bypassing agents: observations from the Dosing Observational Study in Hemophilia (DOSE)
}

This article was published in the following Dove Press journal: Journal of Blood Medicine

20 August 2014

Number of times this article has been viewed

\section{Jennifer Maahs' \\ Jennifer Donkin² \\ Michael Recht ${ }^{3}$ \\ David L Cooper ${ }^{4}$}

'Indiana Hemophilia and Thrombosis Center, Indianapolis, IN, ${ }^{2} \mathrm{Hemostasis}$ and Thrombosis Center, Children's Hospital Los Angeles, Los Angeles, CA, ${ }^{3}$ Oregon Hemophilia Center, Oregon Health and Science University, Portland, OR, ${ }^{4}$ Novo Nordisk,

Princeton, NJ, USA
Correspondence: Jennifer Maahs Indiana Hemophilia and Thrombosis Center, 8402 Harcourt Road, Suite 500, Indianapolis, IN 46260, USA

$\mathrm{Tel}+\mathrm{I} 31787$ I 001 I

Fax +I 3178704540

Email jmaahs@ihtc.org
Abstract: DOSE (Dosing Observational Study in Hemophilia) was a prospective, observational diary study designed to evaluate the use of bypassing agents in patients prescribed recombinant activated factor VII (rFVIIa) as first-line treatment in the home setting. Patients with congenital hemophilia with inhibitors and caregivers participated, and as part of the study, the time spent preparing and administering product was recorded for bypassing agent (BPA) infusions. The aim of this manuscript is to present the results of the analysis of the time spent preparing and administering a single dose of either rFVIIa or plasma-derived activated prothrombin complex concentrate (pd-aPCC). Diaries were completed for 18 adult patients and 19 caregivers of 21 children with 176 BPA-treated bleeding episodes and 1,350 BPA infusions (1,270 rFVIIa, 80 pd-aPCC). The median preparation and administration times were 5.0 minutes and 5.0 minutes for rFVIIa and 29.0 minutes and 24.5 minutes for pd-aPCC, respectively. Preparation and administration times were significantly shorter with rFVIIa than pd-aPCC $(P<0.0001)$. The significantly shorter combined preparation and administration time of rFVIIa, taking into consideration the fasterthan-recommended aPCC infusion rates, suggests that rFVIIa permits a rapid and safe initiation of treatment once a bleeding episode is identified and a decision is made to treat at home.

Keywords: congenital hemophilia, inhibitors, bypassing agent, recombinant-activated factor VIIa, home treatment

\section{Introduction}

Congenital hemophilia is a rare disease that places a considerable burden on patients and their caregivers. The treatment of congenital hemophilia may be complicated by the development of alloantibody inhibitors when clotting factors VIII or IX are administered. For patients with inhibitors, bleeding episodes can be managed with infusions of bypassing agents (BPAs) such as recombinant activated factor VII (rFVIIa; NovoSeven ${ }^{\circledR}$ RT; Novo Nordisk, Bagsvaerd, Denmark) or plasma-derived activated prothrombin complex concentrate (pd-aPCC; FEIBA NF; Baxter, Deerfield, IL, USA). ${ }^{1,2}$

The treatment of bleeding episodes has largely switched from infusions at hemophilia-treatment centers to infusions at home by the patient or caregiver. ${ }^{3}$ In an unrelated phase IIIB home-treatment study, rFVIIa was shown to be effective in more than $90 \%$ of mild-to-moderate bleeding episodes in patients with hemophilia A or B complicated by inhibitors; ${ }^{4}$ this has been confirmed with real-world clinical data from US and global registries. ${ }^{5,6}$ Though efficacy was shown to be a differentiating factor between BPAs in one comparative study ${ }^{7}$ where there was significantly less need for rescue medication with rFVIIa than with pd-aPCC, other studies with different methodologies have not confirmed the difference. ${ }^{8}$ 
The typical dose of rFVIIa recommended to treat a bleeding episode has less volume than does the recommended dose of pd-aPCC, ${ }^{1,2}$ and the recommended infusion time is also shorter for rFVIIa, at $2-5$ minutes ( $90 \mu \mathrm{g} / \mathrm{kg}$ dose $){ }^{1}$ than for pd-aPCC; it is recommended that the infusion rate for pd-aPCC should not exceed $2 \mathrm{U} / \mathrm{kg}$ per minute or 25-50 minutes (50-100 U/kg doses). ${ }^{2}$

DOSE (Dosing Observational Study in Hemophilia) was a prospective, observational diary study designed to evaluate the use of bypassing agents in patients prescribed rFVIIa as first-line treatment in the home setting, ${ }^{9}$ the primary results of which have been published previously. ${ }^{9-12}$ DOSE's planned secondary analyses presented here focus on time spent preparing and administering a single dose of either rFVIIa or pd-aPCC.

\section{Materials and methods Study design and population}

In summary, DOSE was a phase IV observational diary study conducted between January 2008 and July 2009 at 20 federally designated hemophilia treatment centers in the US. ${ }^{9}$ The study population included male patients with hemophilia with inhibitors or parents of male children with hemophilia with inhibitors who were prescribed rFVIIa as first-line therapy for on-demand treatment of bleeds or for treatment of breakthrough bleeding during prophylaxis or immune tolerance induction (ITI) therapy. Eligible patients were required to have had at least four bleeding episodes of any type in the prior 3 months, and had to be willing to complete a detailed daily journal for at least 90 days.

\section{Treatment regimen}

No treatments were specified in this study. All patients received standard care according to local practice and existing BPA prescriptions, and all treatment decisions were made by the individual health care providers, who did not have access to the patient or caregiver diaries. The routine administration of BPAs on nonbleed days (eg, prophylaxis) was not recorded.

\section{Patient diaries}

Patients or caregivers were asked to complete daily diary records for at least 90 days and until four bleeding episodes were experienced by the patient. On days with bleeding episodes, bleed forms were used to capture details of the bleeding episodes (ie, time of bleeding start, symptoms, cause, type, location, time of bleeding stop), BPA administered, and (specific to this analysis) the time spent mixing and administering each BPA dose.

\section{Statistical analyses}

Statistical analyses were largely descriptive and correlative in nature, and were performed by Outcome Sciences (Boston, MA, USA) using SAS 9.2 (SAS Institute, Cary, NC, USA). Simple unpaired $t$-tests were performed for comparisons between groups.

\section{Results}

\section{Patient demographics, diaries, and bleeding episodes}

Detailed analyses of patient demographics have been published previously. ${ }^{9}$ Overall, 52 patients enrolled in the study, and 39 of them completed the daily diaries. ${ }^{12}$ In the enrolled population, 37 reported receiving rFVIIa as on-demand-only treatment, five received ITI, and 12 received prophylaxis with BPAs; two patients were in both the ITI and prophylaxis groups. ${ }^{9-11}$ Approximately half (52\%) of the enrolled population were older than 18 years.

Overall, 18 adult patients completed diaries (2,059 diary days), and 19 caregivers completed 21 diaries for their children (2,004 diary days); ${ }^{9} 24$ participants reported receiving rFVIIa as on-demand-only treatment, five received ITI, and 12 received prophylaxis with BPAs (two patients were in both the ITI and prophylaxis groups). Thirty-eight patients reported 194 bleeding episodes (131 joint bleeds), and accumulated a total of 491 bleed days. ${ }^{12}$ Most bleeding episodes $(176,91 \%)$ were treated with either rFVIIa and/or pd-aPCC, whereas the treatments for the remaining 18 bleeding episodes were not reported. ${ }^{9}$ Of the bleeding episodes treated with BPAs, most were treated with rFVIIa $(152,86.4 \%) ; 18(10.2 \%)$ were treated with pd-aPCC and six (3.4\%) with both rFVIIa and pd-aPCC.

\section{Preparation and administration times for bypassing agents}

The median time spent on preparing and administering BPAs was 5.0 minutes and 5.0 minutes, respectively, for rFVIIa ( $n=1,270$ injections) and 29.0 minutes and 24.5 minutes, respectively, for pd-aPCC ( $\mathrm{n}=80$ injections) (Table 1). Both preparation and administration times were significantly shorter with rFVIIa than with pd-aPCC for the treatment of joint bleeds $(P<0.0001)$ and all bleeds $(P<0.0001)$ (Table 1). This difference, which is consistent with the package-insert instructions for the preparation and administration of both rFVIIa and pd-aPCC, ${ }^{1,2}$ was significant across 
Table I Preparation and administration time of rFVIla and pd-aPCC

\begin{tabular}{|c|c|c|}
\hline & $\begin{array}{l}\text { Joint bleeds } \\
(n=I, 010)\end{array}$ & $\begin{array}{l}\text { All bleeds } \\
(n=1,350)\end{array}$ \\
\hline rFVIIa & $n=952$ & $n=1,270$ \\
\hline \multicolumn{3}{|c|}{ Preparation/mixing (minutes) } \\
\hline Mean (SD) & $6.1(4.2)^{\mathrm{a}}$ & $6.5(4.6)^{\mathrm{a}}$ \\
\hline Median (range) & $5.0(1.0-38.0)$ & $5.0(1.0-38.0)$ \\
\hline \multicolumn{3}{|c|}{ Administration/infusion (minutes) } \\
\hline Mean (SD) & $5.4(4.4)^{\mathrm{a}}$ & $5.7(4.3)^{\mathrm{a}}$ \\
\hline Median (range) & $5.0(1.0-60.0)$ & $5.0(1.0-60.0)$ \\
\hline pd-aPCC & $\mathrm{n}=\mathbf{5 8}$ & $n=80$ \\
\hline \multicolumn{3}{|c|}{ Preparation/mixing (minutes) } \\
\hline Mean (SD) & $22.9(12.6)^{\mathrm{a}}$ & $23.2(14.1)^{\mathrm{a}}$ \\
\hline Median (range) & $20.0(3.0-55.0)$ & $29.0(3.0-60.0)$ \\
\hline \multicolumn{3}{|c|}{ Administration/infusion (minutes) } \\
\hline Mean (SD) & $32.6(24.6)^{\mathrm{a}}$ & $30.8(23.7)^{\mathrm{a}}$ \\
\hline Median (range) & $28.0(5.0-60.0)$ & $24.5(5.0-60.0)$ \\
\hline
\end{tabular}

Note: $\mathrm{a}<0.000 \mathrm{I}$ for $\mathrm{rFVlla}$ versus $\mathrm{pd}-\mathrm{aPCC}$ according to unpaired $t$-test. Abbreviations: $\mathrm{rF}$, recombinant factor; pd-aPCC, plasma-derived activated prothrombin complex concentrate; SD, standard deviation.

all infusions and for infusion patients receiving on-demand treatment only.

\section{Discussion}

DOSE was designed to understand the decision-making process occurring in the home-treatment setting, and to gain insights from the experience of patients and caregivers with managing the patient's own disease. Much as the overall study aimed to correlate prescribed versus actual treatment, ${ }^{12}$ this planned secondary analysis was designed to examine patient and caregiver adherence to standard recommendations for product-infusion rates, thus allowing for more rapid administration of rFVIIa doses.

World Federation of Hemophilia guidelines recommend early treatment of acute bleeding, ideally within 2 hours; these guidelines have been adopted globally by national patient organizations and individual health care providers as an aspirational standard. ${ }^{13}$ To date, there are no good data or clinical studies in patients with or without inhibitors to specifically define inflection points for early intervention that impacts outcome (eg, 30 minutes after recognition of a joint bleed). For ethical reasons, it is not possible to study this prospectively, and retrospective data have too many covariates.

In patients with inhibitors, earlier treatment of acute joint bleeding has been shown to be associated with greater success in terms of response and fewer doses needed for treatment. ${ }^{14}$ An analysis of HemoRec registry data from the Czech Republic showed that bleeding episodes that were treated with rFVIIa within 2 hours of bleed onset showed less rebleeding compared to those treated after 2 hours (5.2\% versus $13.7 \%$, respectively; $P=0.113) .{ }^{15}$ Of the 77 bleeding episodes in the HemoRec registry treated within 2 hours of bleed onset, $50(64.9 \%)$ were treated within the first hour. ${ }^{15}$

Irrespective of whether the patient has product available at room temperature with them when bleed symptoms are recognized, once a decision to treat is made, a shorter producthandling time for mixing and administration should facilitate earlier treatment. The significantly shorter combined preparation and administration time of rFVIIa (10 minutes versus 53.5 minutes) shown in the present study suggests that the use of room-temperature-stable rFVIIa in a home setting may allow for more rapid initiation of treatment once a bleed is recognized and treatment initiated. Further, this might reduce the overall time spent manipulating BPA product across the multiple doses required for most bleeding episodes.

Data interpretation in the present analysis may be limited by several factors, including the inherent bias in the sample size of patients receiving pd-aPCC for bleed treatment, due to the desired inclusion of patients on first-line rFVIIa treatment; this resulted in few pd-aPCC doses available for analysis. The rFVIIa infusion times did not differ greatly from the recommended infusion rate; however, based on an average pd-aPCC dose of $75 \mathrm{U} / \mathrm{kg}$, an infusion time of 35-40 minutes would be expected. This is approximately a third less than the recommended time. ${ }^{2}$ This may place the patient at increased risk for adverse events, such as headache, nausea, dizziness, and chills. ${ }^{16}$ Over time, however, standard practice and patient familiarity with administration may cause deviations from recommended pd-aPCC infusion rates.

Mixing and administration for on-demand treatment in a bleeding state is also different than that in a nonbleeding state, and might be impacted by the location of bleeding. Conceptually, self-infusion of an elbow bleed might result in more difficulty with mixing and administration of either product, due to the limited mobility of the affected elbow. While most (131/194) bleeds in DOSE were joint bleeds, further analysis along these lines was limited, as only 14 elbow bleeds were reported by adults and caregivers. How self-infusing patients manage infusions during elbow bleeds remains an interesting question for further study, and could also impact the design of future mixing devices.

\section{Conclusion}

The burden of treatment in hemophilia includes the time required for preparing and administering BPAs, so this 
remains a significant consideration for patients with inhibitors, even as treatment has moved into the home setting. The current study results demonstrate significantly shorter mixing and infusion times with a single dose of rFVIIa compared to a single dose of pd-aPCC. This takes into consideration the faster-than-recommended aPCC infusion rates, suggesting that rFVIIa may permit a more rapid and safe initiation of treatment once a bleeding episode is identified and a decision is made to treat at home.

\section{Acknowledgments}

The authors acknowledge the assistance of Outcome Sciences Inc., a contract research organization that conducted the study and provided statistical analysis with funding by Novo Nordisk Inc. Editorial assistance was provided by Amanda Tricarico, PhD, ETHOS Health Communications, Newtown, PA, with financial assistance from Novo Nordisk Inc., in compliance with international guidelines on good publication practice. These data were presented, in part, at the International Society for Pharmacoeconomics and Outcomes Research 2010 Annual International Meeting.

\section{Disclosure}

JM, JD, and MR are consultants for Novo Nordisk. MR was an investigator, and JD was a study coordinator at a trial site. DLC is an employee of Novo Nordisk. The authors report no other conflicts of interest in this work.

\section{References}

1. Novo Nordisk. NovoSeven RT coagulation factor VIIa (recombinant) room temperature stable [prescribing information]. Princeton (NJ): Novo Nordisk; 2010.

2. Baxter. FEIBA NF (Anti-Inhibitor Coagulant Complex), Nanofiltered and Vapor Heated [package insert]. Deerfield (IL): Baxter; 2011.

3. Teitel JM, Barnard D, Israels S, Lillicrap D, Poon MC, Sek J. Home management of haemophilia. Haemophilia. 2004;10(2):118-133.

4. Key NS, Aledort LM, Beardsley D, et al. Home treatment of mild to moderate bleeding episodes using recombinant factor VIIa (Novoseven) in haemophiliacs with inhibitors. Thromb Haemost. 1998;80(6):912-918.
5. Chambost H, Santagostino E, Laffan M, Kavakli K. Real-world outcomes with recombinant factor VIIa treatment of acute bleeds in haemophilia patients with inhibitors: results from the international ONE registry. Haemophilia. 2013;19(4):571-577.

6. Young G, Cooper DL, Gut RZ. Dosing and effectiveness of recombinant activated factor VII (rFVIIA) in congenital haemophilia with inhibitors by bleed type and location: the experience of the Haemophilia and Thrombosis Research Society (HTRS) Registry (2004-2008). Haemophilia. 2012;18(6):990-996.

7. Young G, Shafer FE, Rojas P, Seremetis S. Single 270 microg $\mathrm{kg}(-1)-$ dose rFVIIa vs standard 90 microg $\mathrm{kg}(-1)$-dose rFVIIa and APCC for home treatment of joint bleeds in haemophilia patients with inhibitors: a randomized comparison. Haemophilia. 2008;14(2):287-294.

8. Astermark J, Donfield SM, DiMichele DM, et al. A randomized comparison of bypassing agents in hemophilia complicated by an inhibitor: the FEIBA NovoSeven Comparative (FENOC) study. Blood. 2007;109(2):546-551.

9. Young G, Solem CT, Hoffman K, et al. Capturing daily assessments and home treatment of congenital hemophilia with inhibitors: design, disposition, and implications of the Dosing Observational Study in Hemophilia (DOSE). J Blood Med. 2012;3:131-138.

10. Gruppo RA, Kessler CM, Neufeld EJ, Cooper DL. Assessment of individual dose utilization vs physician prescribing recommendations for recombinant activated factor VII (rFVIIa) in paediatric and adult patients with congenital haemophilia and alloantibody inhibitors (CHwI): the Dosing Observational Study in Hemophilia (DOSE). Haemophilia. 2013;19(4):524-532.

11. Neufeld EJ, Recht M, Sabio H, et al. Effect of acute bleeding on daily quality of life assessments in patients with congenital hemophilia with inhibitors and their families: observations from the dosing observational study in hemophilia. Value Health. 2012;15(6):916-925.

12. Young G, Shapiro AD, Walsh CE, Gruppo RA, Gut RZ, Cooper DL. Patient/caregiver-reported recombinant factor VIIa (rFVIIa) dosing: home treatment of acute bleeds in the Dosing Observational Study in Hemophilia (DOSE). Haemophilia. 2012;18(3):392-399.

13. Srivastava A, Brewer AK, Mauser-Bunschoten EP, et al. Guidelines for the management of hemophilia. Haemophilia. 2013;19(1):e1-e47.

14. Lusher JM. Acute hemarthroses: the benefits of early versus late treatment with recombinant activated factor VII. Blood Coagul Fibrinolysis. 2000;11 Suppl 1:S45-S49.

15. Salaj P, Brabec P, Penka M, et al. Effect of rFVIIa dose and time to treatment on patients with haemophilia and inhibitors: analysis of HemoRec registry data from the Czech Republic. Haemophilia. 2009;15(3):752-759.

16. Hilgartner MW, Knatterud GL. The use of factor eight inhibitor by-passing activity (FEIBA immuno) product for treatment of bleeding episodes in hemophiliacs with inhibitors. Blood. 1983;61(1):36-40.
Journal of Blood Medicine

\section{Publish your work in this journal}

The Journal of Blood Medicine is an international, peer-reviewed, open access, online journal publishing laboratory, experimental and clinical aspects of all topics pertaining to blood based medicine including but not limited to: Transfusion Medicine; Blood collection, Donor issues, Transmittable diseases, and Blood banking logistics; Immunohematology; Artificial and alternative

\section{Dovepress}

blood based therapeutics; Hematology; Biotechnology/nanotechnology of blood related medicine; Legal aspects of blood medicine; Historical perspectives. The manuscript management system is completely online and includes a very quick and fair peer-review system. Visit http://www.dovepress.com/ testimonials.php to read real quotes from published authors. 